\title{
Pork meat increases iron absorption from a 5-day fully controlled diet when compared to a vegetarian diet with similar vitamin $C$ and phytic acid content
}

\author{
Mette Bach Kristensen ${ }^{1}$, Ole Hels ${ }^{1}$, Catrine Morberg ${ }^{1}$, Jens Marving ${ }^{2}$, Susanne Bügel ${ }^{1}$ and Inge Tetens ${ }^{1}$ \\ ${ }^{1}$ Department of Human Nutrition, Centre for Advanced Food Studies (LMC), The Royal Veterinary and Agricultural University, \\ Frederiksberg, Denmark \\ ${ }^{2}$ Department of Clinical Physiology and Nuclear Medicine, Rigshospitalet, University of Copenhagen, Denmark
}

(Received 14 September 2004 - Revised 22 December 2004 - Accepted 5 January 2005)

\begin{abstract}
Meat increases absorption of non-haem iron in single-meal studies. The aim of the present study was to investigate, over a $5 \mathrm{~d}$ period, the potential increasing effect of consumption of pork meat in a whole diet on the fractional absorption of non-haem iron and the total absorption of iron, when compared to a vegetarian diet. A randomised cross-over design with $3 \times 5 \mathrm{~d}$ whole-diet periods with diets containing Danish-produced meat, Polish-produced meat or a vegetarian diet was conducted. Nineteen healthy female subjects completed the study. All main meals in the meat diets contained $60 \mathrm{~g}$ of pork meat and all diets had high phytic acid content $(1250 \mu \mathrm{mol} / \mathrm{d})$. All main meals were extrinsically labelled with the radioactive isotope ${ }^{59} \mathrm{Fe}$ and absorption of iron was measured in a whole body counter. The non-haem iron absorption from the Danish meat diet was significantly higher compared to the vegetarian diet $(P=0.031)$. The mean fractional absorption of non-haem iron was 7.9 (SE1.1), 6.8 (SE 1.0) and 5.3 (SE 0.6) \% for the Danish and Polish meat diets and vegetarian diet, respectively. Total absorption of iron was higher for both meat diets compared to the vegetarian diet (Danish meat diet: $P=0.006$, Polish meat diet: $P=0.003$ ). The absorption ratios of the present study were well in accordance with absorption ratios estimated using algorithms on iron bioavailability. Neither the meat diets nor the vegetarian diets fulfilled the estimated daily requirements of absorbed iron in spite of a meat intake of $180 \mathrm{~g} / \mathrm{d}$ in the meat diets.
\end{abstract}

$\mathrm{Fe}^{59}$ : Whole body counting: Bioavailability: Radioisotopes: Women

A high prevalence of low iron stores in both developing and industrialised countries has led to substantial research in investigating possible factors influencing iron status. Several factors influence the amount of iron absorbed from the diet, the iron status of the subject and the bioavailability of iron from the diet consumed (Wienk et al. 1999; Reddy et al. 2000; Heath \& Fairweather-Tait, 2002). An enhancing effect of vitamin C (Hallberg et al. 1986, 1989) and an inhibiting effect of phytic acid (Hallberg et al. 1987; Brune et al. 1992) and polyphenols (Hallberg \& Rossander, 1982a; Morck et al. 1983; Samman et al. 2001) on the absorption of non-haem iron have been well established. Meat provides a good source of minerals and has a dual role in relation to daily iron supply due to the high bioavailability of haem iron in muscle tissue and the enhancing effect on the bioavailability of non-haem iron as shown in early studies (Layrisse et al. 1969; Martinez-Torres \& Layrisse, 1971; Björn-Rasmussen \& Hallberg, 1979). A recent study showed a significant increase in non-haem iron absorption from a phytic acid-rich meal when a minimum of $50 \mathrm{~g}$ of pork meat was consumed (Bæch et al. 2003) and another study found that a meat-containing diet was highly significantly correlated with iron absorption when estimating iron bioavailability from different meal compositions (Reddy et al. 2000). All mentioned observations are based on single-meal studies. The enhancing factor of muscle tissue remains elusive and is generally referred to as the 'meat factor'.
A discrepancy in the absorption ratio of non-haem iron has occurred when comparing results from single-meal studies and whole-diet studies, indicating that the results from single-meal studies overestimate the effects on enhancers and inhibitors in the diet of iron absorption (Cook et al. 1991), and that shortterm measurements of absorption overestimate differences in iron bioavailability between diets (Hunt \& Roughead, 2000).

Except for the single-meal study by Bæch et al. (2003) studies on the 'meat effect' on iron absorption have mainly been conducted with meals with varying phytic acid and vitamin $\mathrm{C}$ contents, which makes it difficult to quantify the 'meat effect' per $s e$. The aim of the present study was therefore to investigate the potential enhancing effect of consumption of pork meat in a whole diet of five consecutive days on the fractional absorption of non-haem iron and the total absorption of iron, when compared to a vegetarian diet with equal phytic acid contents. The pork meat was produced by conventional production systems in Denmark and in Poland.

\section{Subjects and methods}

\section{Subjects}

The inclusion criteria of the present study were women from 18 to 40 years of age, omnivores, non-smoking, not pregnant or lactating 
nor exercising heavily and with low iron stores. Three subjects dropped out, all within the first week. One disliked the food served and two due to lack of time. The nineteen subjects who completed the study were aged 25.0 (SE 5.2) years, had BMI of 22.6 (SE 3.5), with screening serum ferritin levels between 12 and $30 \mu \mathrm{g} / \mathrm{l}$ and haemoglobin levels $>110 \mathrm{~g} / \mathrm{l}$. The subjects were not allowed to take any medication or vitamin, mineral or other supplements nor to donate blood during, and at least 2 months prior to, the study. Eleven subjects took oral contraceptives and two used an intrauterine device.

\section{Human study design}

The absorption of non-haem iron was measured in a cross-over design with three types of full-day diets, two meat diets and a vegetarian diet during three $5 \mathrm{~d}$ periods (Monday to Friday). The study was conducted in two periods from February to May and September to November 2003. The study design is illustrated in Fig. 1. Subjects were randomly assigned to the order in which the meals were received and study periods were separated by a 3 -week washout period. Subject's individual weight was recorded at the baseline and prior to the final whole-body counting, using the same digital scale.

All diets consisted of a basic diet with low iron bioavailability, containing high amounts of phytic acid and a low vitamin C content. The two meat diets contained either of two meat sources (Longissimus dorsi from pigs produced in Poland or Denmark) and breakfast, lunch and dinner each contained $60 \mathrm{~g}$ of meat. The vegetarian diet was served with carbonated drinks replacing the energy corresponding to the meat. Full-day diets had an energy content of 9,10 or $11 \mathrm{MJ}$ matching the estimated basal metabolic rate and physical activity of the individual subject and did not differ between the respective study periods.

Breakfast, lunch and dinner meals were extrinsically labelled with ${ }^{59} \mathrm{Fe}$ and served at the Department of Human Nutrition. A $2 \mathrm{~d}$ menu cycle was served throughout the week (Table 1) and did not differ between study periods. Subjects were not allowed to consume anything apart from the served meals and evening snack, but were allowed to consume ad libitum mineral water (Harilds Kilde, Ringe, Denmark) and instructed to consume the same quantity of mineral water on the respective days of the individual study periods.

Blood samples were taken at screening and during the second and third study period for analysis of serum ferritin (Fig. 1).

\section{Experimental diet}

Meat was obtained from the Danish Institute of Agricultural Sciences, Foulum, Denmark and the Kielanowski Institute of Animal Physiology and Nutrition, Poland, as part of the 5th
Table 1. Composition of a $2 \mathrm{~d}$ menu cycle of a whole-day diet of $10 \mathrm{MJ}^{*}$

\begin{tabular}{lcc}
\hline & Meat diet $(\mathrm{g})$ & Vegetarian diet $(\mathrm{g})$ \\
\hline Breakfast & & \\
Whole grain wheat bread & 100 & 100 \\
Pâté & 106 & 54 \\
Butter & 15 & 15 \\
Marmalade (raspberry/apricot) & 20 & 20 \\
Raisins & 25 & 25 \\
Carbonated drinks & - & 195 \\
Lunch & 100 & \\
Whole grain wheat bread & 106 & 100 \\
Pâté $†$ & 15 & 54 \\
Butter & $30 / 40$ & 15 \\
Beetroot (pickled)/carrot & - & $30 / 40$ \\
Carbonated drinks & & 195 \\
Dinner & 80 & 80 \\
Whole grain pasta/brown riceł & 250 & 205 \\
Casserole§ & 40 & 40 \\
Whole grain wheat bread & - & 195 \\
Carbonated drinks & & \\
Snack & 49 & 49 \\
Chocolate & 75 & 160 \\
Dried apricots & 160 & \\
Apple/pear & &
\end{tabular}

*Breakfast, lunch and dinner each contained $60 \mathrm{~g}$ of pork meat in the meat diets (raw weight).

†Pork (only in meat diets), rapeseed oil, eggs, spinach, parsley, mushroom, almond, onion, coriander, gelatine, salt.

‡Raw weight.

$\S$ Pork (only in meat diets), rapeseed oil, mushroom, carrot, canned tomato, tomato purée, onion, garlic, beer, salt.

framework project SUSPORKQUAL. The meat was from crossbred pigs, Duroc boar and Landrace $\times$ Yorkshire sow. It was previously shown that the pork meat produced in Poland had a higher content of iron and zinc than the pork meat produced in Denmark (Fandrejewski et al. 2004). The meat was trimmed of visible fat and connective tissues and minced with stainless steel knives in a meat grinder and meat pâtés and casseroles were prepared immediately afterwards. All meals were prepared in a specially designed kitchen to minimise mineral contamination and each dietary item was apportioned at an accuracy of $0.5 \mathrm{~g}$ and frozen. Remaining dietary items were purchased in one batch, except for the wholewheat bread, carrots and fruit, which were purchased in two batches.

Before the first meal of each study period, the subject had fasted for $12 \mathrm{~h}$ and was only allowed to consume 0.5 litre of water. Consumption of alcohol was not permitted $24 \mathrm{~h}$ before a study period. The meals were thawed at $5^{\circ} \mathrm{C}$ overnight before serving and were extrinsically labelled by adding $1 \mathrm{ml}$ of radioisotopic solution $\left(\mathrm{FeCl}_{3}\right.$ in $0.1 \mathrm{~mol} / \mathrm{l} \mathrm{HCl}$; Ris $\varnothing$ National Laboratory, Roskilde, Denmark) to the main course $>16 \mathrm{~h}$ prior to consumption. Only one staff member was in charge of the labelling

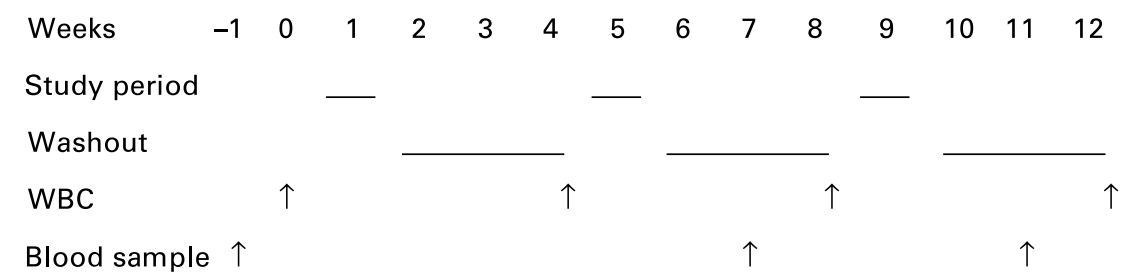

Fig. 1. Design of the study, showing three study periods of $5 \mathrm{~d}$ with $21 \mathrm{~d}$ of washout and four whole-body-counting (WBC) for measurements of iron absorption and blood sample for analysis of serum ferritin. 
throughout the study. Each subject received a total activity amount of $120 \mathrm{kBq}{ }^{59} \mathrm{Fe}$, giving an effective dose of $0.22 \mathrm{mSv}$, from a total of forty-five meals in the study. Meals were served at fixed intervals (breakfast 07.30-08.30 hours; lunch 12.0013.00 hours; dinner $17.00-18.30$ hours) and $400 \mathrm{ml}$ of mineral water were served with each meal. Subjects were instructed to wipe off their plates with the bread served to ensure a complete intake of the isotope dosage. A staff member ensured that everything was consumed. Subjects were not allowed to drink mineral water $30 \mathrm{~min}$ before and $1 \mathrm{~h}$ after a meal. The evening snack was handed out at the evening meal and consumed outside the Department a minimum of $3 \mathrm{~h}$ after the evening meal.

Content of energy, protein, fat, carbohydrate, vitamin $\mathrm{C}$ and calcium was calculated using the Dankost $2000^{\circledR}$ dietary assessment software (Danish Catering Center, Herlev, Denmark).

\section{Blood sampling}

Blood samples were taken at screening for participation in the study and at the second and third week of intervention. A total of three blood samples of $10 \mathrm{ml}$ were drawn from the cubital vein from each subject in the morning after an overnight fast (intake of 0.5 litre of mineral water was allowed) after an additional $10 \mathrm{~min}$ rest in the supine position. In order to prevent artificially high values of serum ferritin due to infections, subjects were carefully instructed to report any sign of self-reported infection at the time of blood sampling. In the case of infection blood samples were postponed until $14 \mathrm{~d}$ after the end of infection as judged by the subject.

\section{Determination of iron absorption}

Non-haem iron absorption from the full-day diets was estimated by whole-body retention of ${ }^{59} \mathrm{Fe} 21 \mathrm{~d}$ after consumption of extrinsically labelled meals, measured in a lead-lined steel chamber with four NE110 plastic scintillated blocks (Nuclear Enterprises Ltd, Edinburgh, UK) connected to conventional nuclear electronic modules and a multichannel analyser system. The counting efficiency and energy window settings were established through measurements of water-filled phantoms whose weights were equal to those of the subjects of the present study. The phantoms were filled with the amount of isotope corresponding to the amount received by each subject. In the actual setup and with the energy window used, the overall counting efficiency for ${ }^{59} \mathrm{Fe}$ evenly distributed in a $77 \mathrm{~kg}$ phantom was $\sim 20 \%$. To minimise contamination by atmospheric background activity, all subjects had a shower, washed their hair and were dressed in hospital clothing before each measurement. The counting time was $10 \mathrm{~min}$, and the results were corrected for chamber background radiation and the subject's background radiation radioisotope level measured $3 \mathrm{~d}$ before the beginning of the first intervention period. All results from the determination of radioactivity measurements were corrected for the physical decay of the isotope.

Non-haem iron absorption was expressed as fractional absorption (percentage of total amount ingested). Haem iron absorption was calculated from the inverse logarithmic function between iron stores and absorption of haem iron estimated by Monsen et al. (1978). The haem iron absorption of the subjects in the present study was estimated to $30 \%$.
Equations 1 and 3 were developed by Reddy et al. (2000) and Hallberg \& Hulthen (2000), respectively, to estimate the absorption of non-haem iron from a meal, based on the concentration of animal tissue, phytic acid and ascorbic acid. The enhancing effect of meat and inhibiting effect of phytic acid in the present study was estimated through the algorithms:

$$
\begin{aligned}
\ln \left[\text { Abs } \%_{(\text {AdjSF30 })}\right]= & 1.9786+(0.0123 \times \text { AT })-(0.0034 \\
& \times \text { PA })+(0.0065 \times \text { AA })
\end{aligned}
$$

where Abs \% is adjusted to a serum ferritin of 30, AT is animal tissue (g, meat or fish, cooked weight), PA is phytic acid (mg) and AA is ascorbic acid (mg). Absorption was adjusted to a serum ferritin of $30 \mu \mathrm{g} / \mathrm{l}$ calculated from Cook et al. (1991):

$$
\log \mathrm{A}_{\text {adj usted }}=\log \mathrm{A}_{\text {measured }}+\log \mathrm{SF}-\log _{30}
$$

where $\mathrm{SF}$ is the concentration of serum ferritin $(\mu \mathrm{g} / \mathrm{l})$ expressed as the average of three blood samples.

Ratio of absorption with and without meat

$$
=1+(0.00628 \times \mathrm{M}) \times[1+(0.006 \times \mathrm{P})]
$$

where $\mathrm{M}$ is raw meat, poultry or fish, and $\mathrm{P}$ is phytate-phosphorus (mg).

\section{Chemical analyses}

All dietary items of the $2 \mathrm{~d}$ menu cycle were homogenised and lyophilised before chemical analysis. Content of iron was analysed in triplicate in portions of the $10 \mathrm{MJ}$ diets (Knudsen et al. 1996). The diets were microwave digested (MES-1000, CEM Corporation, Matthews, NC, USA) with $\mathrm{HNO}_{3} 65 \%$, suprapur (Merck, Darmstadt, Germany) and $\mathrm{H}_{2} \mathrm{O}_{2} 30 \%$, suprapur (Merck). Iron was measured by atomic absorption spectroscopy Spectra AA-200 Varian (Varian Techtron Pty Ltd, Victoria, Australia). Iron standards were prepared from a $1000 \mathrm{mg} / \mathrm{l} \mathrm{Fe}$ standard (Tritisol ${ }^{\circledR}$; Merck) and a reference diet (Standard Reference Material 1548a, Typical Diet, National Institute of Standards and Technology, Gaithersburg, MD, USA) was analysed in the same run with a certified value of $35.3($ SE $3.77 \mu \mathrm{g} / \mathrm{g}$ ). Analysed values were 34.5 (SE 1.9) $\mu \mathrm{g} / \mathrm{g}(n$ 2).

Non-haem iron content of the meat was analysed in triplicate according to the ferrozine method described by Ahn et al. (1993). Haem iron content was calculated as the difference between total iron content and non-haem iron content of the meat.

The content of phytic acid in the whole diets was determined from the method of Carlsson et al. (2001).

Blood was collected in dry tubes for analysis of serum ferritin concentration and in EDTA tubes for analysis of haemoglobin concentration (BD Vacutainer System, Benson Dickinson, Franklin Lakes, NJ, USA). Serum ferritin was analysed in duplicate by a solid-phase, two-site fluoroimmunometric assay using a AutoDELFIA $^{\text {TM }}$ System (1235-514; Wallac Oy, Turku, Finland). Intra-assay and inter-assay coefficients of variation of internal control $(n$ 11) were 3.5 and $3.6 \%$, respectively. Haemoglobin concentration was analysed by photometric absorptiometry (with sodium lauryl sulphate) on a Sysmex KX-21 (Sysmex Corporation, Kope, Japan). Intra-assay (n 12) and inter-assay ( $n$ 27) coefficients of variation of external control HEM 2002 were 0.6 
and $0.6 \%$, respectively. All blood samples from the individual subjects were analysed within the same run.

\section{Ethics}

All subjects were informed, orally and in writing, about the study. Written consent of participation, stating that the subject participated voluntarily and was free to withdraw from the study at any time, was obtained before enrolment. The study protocol was approved by the Ethics Committee of Copenhagen and Frederiksberg (authorisation number (KF) 01-197/02) and the National Institute of Radiation Hygiene, Denmark.

\section{Statistics}

All analyses and calculations were performed using the Strategic Analysis System software package, version 8.2 (SAS Institute, Cary, NC, USA). Univariate mixed model ANOVAs were performed in the procedure MIXED. In the statistical model, the iron absorptions measured at the end of each period were evaluated as the dependent variable. Treatment, order, period and treatment $\times$ order were included as independent fixed variables. Subjects were included as a random effect. Homogeneity of variance and normal distribution among random effects were investigated by plots of residuals. Shapiro-Wilk's test for normal distribution was performed.

\section{Results}

All meals were consumed at the Department under the supervision of a staff member and compliance to the three dietary intervention periods was high. All subjects remained weight stable throughout the study.

The serum ferritin concentration at screening was $19 \mu \mathrm{g} / \mathrm{l}$ (12-28) (geometric mean, range) and the geometric mean of serum ferritin concentration of the three blood samples taken in the study was $15.2 \mu \mathrm{g} / \mathrm{l}(8.9-29.7 \mu \mathrm{g} / \mathrm{l})$. Mean haemoglobin at screening was 125 (SE 3.3) g/l.

The nutrient composition of the $10 \mathrm{MJ}$ diets is outlined in Table 2. Approximately $30 \%$ of the daily vitamin C intake was consumed at the evening snack, which was the only meal not extrinsically labelled with radioisotopes. Protein and fat content was higher in the meat diets, since the equivalent energy contribution from the meat was substituted by carbonated drinks.

The total iron content of the meat was $0.14 \mathrm{mg} / 100 \mathrm{~g}$ and $0.20 \mathrm{mg} / 100 \mathrm{~g}$ and the haem iron concentration of the Danish and Polish produced meat was 38 and $45 \%$, respectively, and

Table 2. Energy, macronutrient, micronutrient and phytic acid content of a $10 \mathrm{MJ}$ diet

\begin{tabular}{lrc}
\hline & Meat diets & Vegetarian diet \\
\hline Protein $(\mathrm{g})$ & 84 & 48 \\
Fat $(\mathrm{g})$ & 85 & 76 \\
Carbohydrate $(\mathrm{g})$ & 310 & 370 \\
Dietary fibre $(\mathrm{g})$ & 29 & 29 \\
Vitamin C $(\mathrm{mg})$ & 51 & 51 \\
Calcium $(\mathrm{mg})$ & 430 & 540 \\
Phytic acid $(\mu \mathrm{mol})^{*}$ & 1280 & 1160 \\
\hline
\end{tabular}

${ }^{*}$ Analysed values the subjects received a daily amount of haem iron of 0.25 and $0.36 \mathrm{mg}$. The haem iron absorption of the subjects in the present study is estimated to $30 \%$ resulting in haem iron absorption of 0.08 and $0.11 \mathrm{mg} / \mathrm{d}$ for the Danish meat diet and Polish meat diet, respectively. The daily intake of $180 \mathrm{~g}$ of meat contributed to 6.6 and $7.6 \%$ of the total intake of iron in the meat diets. Contents of iron were evenly distributed between the four meals of the day.

The fractional and total absorption of iron from the Danish meat diet, Polish meat diet and vegetarian diet are listed in Table 3. The fractional absorption of non-haem iron was increased by $2.6 \%$ from the Danish meat diet compared to the vegetarian diet $(P=0.012)$. The fractional absorption of nonhaem iron from the Polish diet was $1.5 \%$ higher compared to the vegetarian diet, which was not statistically different. When the two meat diets are not differentiated in the statistical analysis, the fractional non-haem iron absorption is increased when compared to the vegetarian diet $(P=0 \cdot 02)$.

Total iron absorption was significantly increased by 69 and $54 \%$ in the Danish meat diet and Polish meat diet, respectively, compared to the vegetarian diet. The average increased absorption was $0.36(\mathrm{SE} 0.11) \mathrm{mg} / \mathrm{d}$ in the Danish meat diet $(P=0.006)$ and $0 \cdot 28$ (SE 0.10) $\mathrm{mg} / \mathrm{d}$ in the Polish meat diet $(P=0 \cdot 003)$. No significant difference was observed between the Danish meat diet and the Polish meat diet with regard to both non-haem iron absorption and total iron absorption.

Non-haem iron absorption, when adjusted to a serum ferritin of $30 \mu \mathrm{g} / \mathrm{l}$, is 4.2 (SE 0.62), 3.6 (SE 0.72) and 2.5 (SE 0.39) \% for the Danish meat diet, Polish meat diet and vegetarian diet, respectively. The estimated absorption ratio of the meat-based diet in relation to the non-meat diets was 1.8 and 1.5 from Equations 1 and 3 , respectively. The absorption ratio of the diets with and without meat is 1.5 and 1.3 for the Danish meat diet and Polish meat diet, respectively.

\section{Discussion}

An intake of $60 \mathrm{~g}$ of pork meat at breakfast, lunch and evening meals resulted in an increased fractional non-haem iron absorption from the Danish meat diet but not from the Polish meat diet when compared to the same meal without meat. When the meat diets were combined a significant effect of meat diets on non-haem iron absorption was observed. The fractional absorption of non-haem iron is comparable with other studies on the effect of meat on non-haem iron absorption of young women (Bæch et al. 2003; Hunt, 2003). Total iron absorption was significantly increased from both meat diets when compared to the non-meat diet, resulting in a 50-70\% increase in total iron absorption, in spite of the fact that the meat in both meat diets only contributed to $7 \%$ of the total iron intake in the meat diets.Total iron content was comparable in the two types of meat and the haem iron content differed slightly with a higher content of haem iron in the Polish-produced meat. The reason for the difference in fractional absorption between the two types of meat-based diets cannot be explained by the results of the present study.

The present study holds a strong design to demonstrate the pure meat effect on iron absorption. Only the intake of meat differed between the three diets and enhancers and inhibitors of iron absorption such as vitamin $\mathrm{C}$, phytic acid and polyphenols were kept at a constant level in all diets. All subjects consumed the three intervention diets in a randomised design, minimising the 
Table 3. Total iron intake, the fractional non-haem iron absorption and total iron absorption in whole-day diets from two meat-based diets and the same diet without meat (vegetarian diet)

(Mean values with their standard errors for nineteen subjects)

\begin{tabular}{|c|c|c|c|c|c|c|c|c|}
\hline & \multicolumn{2}{|c|}{ Total iron intake $(\mathrm{mg} / \mathrm{d})$} & \multicolumn{2}{|c|}{$\begin{array}{l}\text { Fractional non-haem } \\
\text { iron absorption (\%) }\end{array}$} & \multicolumn{2}{|c|}{$\begin{array}{l}\text { None-haem iron } \\
\text { absorption (mg/d) }\end{array}$} & \multicolumn{2}{|c|}{$\begin{array}{l}\text { Total iron absorption } \\
(\mathrm{mg} / \mathrm{d})\end{array}$} \\
\hline & Mean & SE & Mean & SE & Mean & SE & Mean & SE \\
\hline Danish meat diet & $10 \cdot 3$ & 0.14 & $7 \cdot 9^{a}$ & $1 \cdot 1$ & $0 \cdot 81^{a}$ & $0 \cdot 12$ & $0.88^{a}$ & 0.12 \\
\hline Polish meat diet & $10 \cdot 2$ & 0.12 & $6 \cdot 8^{\mathrm{ab}}$ & 1.0 & $0.69^{a}$ & $0 \cdot 10$ & $0.80^{\mathrm{a}}$ & 0.10 \\
\hline Vegetarian diet & $9 \cdot 8$ & $0 \cdot 15$ & $5 \cdot 3^{b}$ & 0.6 & $0.52^{b}$ & 0.06 & $0.52^{b}$ & 0.06 \\
\hline
\end{tabular}

${ }^{\mathrm{a}, \mathrm{b}}$ Mean values with different superscript letters within the same column are significantly different $(P<0.05)$.

effects of naturally occurring biological variations. Furthermore, the study periods consisted of five consecutive days of controlled intervention absorption study, which has not, to the author's best knowledge, been reported before. In the vegetarian diets carbonated drinks substituted the energy contribution from the meat. This, however, may be regarded as a limitation to the study if trying to apply the results to a 'real life' situation, since vegetarians most likely consume more bread or fruit and vegetables as a compensator for the lack of meat in the diet, often resulting in a higher vitamin $\mathrm{C}$ intake. Such substitution is likely to result in elevated phytic acid contents of vegetarian meals and thereby a higher proportion of inhibitors in the diet.

The average daily intake of iron of young women of child-bearing age in Denmark is $8.5 \mathrm{mg} / \mathrm{d}$, considerably lower than the recommended intake of $15 \mathrm{mg} / \mathrm{d}$, and below the daily intake of the present study (Andersen et al. 1996). The meat intake in the present study was significantly higher than for the representative Danish population, having a daily meat intake of $83 \mathrm{~g} / \mathrm{d}$ (including fish and poultry the intake is $109 \mathrm{~g} / \mathrm{d}$ ) (Andersen et al. 1996). The results of the present study emphasise the importance of a combination of an increased intake of iron and increased iron bioavailability in the effort of meeting the estimated daily requirements of young women of child-bearing age.

When studying the bioavailability of non-haem iron from a meal composition, Reddy et al. (2000) developed an equation (Equation 1) to estimate the absorption of non-haem iron from a meal, based on the concentration of animal tissue, phytic acid and ascorbic acid. The algorithm was derived from the results of twenty-five different meals including $18-70 \mathrm{~g}$ beef, pork, turkey, chicken or seafood (cod, tuna and shrimp) given to eighty-six subjects in nine studies. Another algorithm (Equation 3 ) for the calculation of the effect of meat on non-haem iron absorption was derived by pooled results from studies investigating beef (mainly 75-100 g) in single-meal radioisotopic studies (Hallberg \& Hulthen, 2000) and was validated with twenty-four meals including beef, pork, cod and shrimp in four different studies (Rossander et al. 1979; Hallberg \& Rossander, 1982b,c; Hulthen et al. 1995). The absorption ratios of the present study are well in accordance with the absorption ratios estimated using both algorithms.

The discussion whether results of iron absorption obtained from single-meal studies are comparable to results obtained over longer periods has been going on for the last decade (Cook et al. 1991; Hunt \& Roughead, 2000). Bæch et al. (2003) studied iron absorption from a meal composition very similar to the one used in the present study (Fe content 2.62, phytic acid $220 \mathrm{mg}$, ascorbic acid $7.4 \mathrm{mg}$ ). Non-haem iron absorption was $2.1 \%$ in the vegetarian meal and $3.3 \%$ with an additional intake of $50 \mathrm{~g}$ pork meat (Bæch et al. 2003). The results are highly comparable to the results of the present study, where the non-haem iron absorption was $2.1 \%$ in the vegetarian diet and 3.3 and $2.7 \%$ for the Danish meat diet and Polish meat diet, respectively, when all values are adjusted to a serum ferritin of 40 . The present study is not of a magnitude to draw definite conclusions on this key issue, but has shown that when investigating non-haem iron absorption in a phytic acid-rich meal, and in a controlled diet, the results of single-meal studies are almost identical to results from whole-meal studies of five consecutive days, which in addition is expressed in the resemblance of absorption ratios with the algorithms of Reddy et al. (2000) and Hallberg \& Hulthen (2000) based on single-meal studies.

In the design of the diets in the present study it was aimed at having a low bioavailability diet, in order to estimate meat as a possible enhancing factor. The total iron intake of a full day diet was on average $10 \mathrm{mg}$, two-thirds of the recommended daily intake of $15 \mathrm{mg} / \mathrm{d}$ for the study population by the Nordic Nutrient Recommendations (Becker, 2004), despite the diets containing wholewheat bread, brown rice and pasta, and a pâté made from freeze-dried parsley and spinach which are foods with high iron contents. Fortification of iron was until recently not permitted within the Danish food market and therefore not a useful remedy to increase iron intake. Daily iron requirements, the amounts of absorbed iron required to prevent development of iron deficiency (Hallberg \& Rossander-Hultén, 1991), are high among young menstruating women and is estimated to be 1.35 and $2.77 \mathrm{mg} / \mathrm{d}$ for the median and 95th percentile, respectively (Becker, 2004). The amount of menstrual blood loss is diminished in users of oral contraceptives and the 95th percentile is estimated to be $1.89 \mathrm{mg} / \mathrm{d}$ (Hallberg \& Rossander-Hultén, 1991). Of the subjects in the present study, $58 \%$ used oral contraceptives. The daily amount of absorbed iron in the present study was low and, based on the estimated daily requirements of $95 \%$ of the study population, the meat diets only covered 30 and $45 \%$ of the non-users and users of oral contraceptives, respectively, and 18 and $30 \%$, respectively, was covered by the non-meat diets. The low absorption rates are most likely due to a combination of a low iron intake and low non-haem iron absorption, which is primarily a consequence of the low bioavailability diet used in the present study. If wholemeal cereals and spinach is consumed in a low vitamin $\mathrm{C}$ diet on a regular basis, iron requirements will be difficult to achieve.

In conclusion, a meat-containing diet resulted in an increased fractional absorption of iron from the Danish meat diet compared to the vegetarian diet and both meat diets resulted in increased 
amounts of total absorbed iron. Neither the meat diets nor the vegetarian diets fulfilled the estimated daily requirements of absorbed iron in spite of a meat intake of $180 \mathrm{~g} / \mathrm{d}$ in the meat diets.

\section{Acknowledgements}

This study is dedicated to the memory of the late Professor Brittmarie Sandström who initiated this work package as part of the 5th frame project SUSPORKQUAL, QLK5-CT-2000-00 162. We thank all the participating subjects for their enthusiasm and interest in the study. The staff of the metabolic kitchen, Berit Hoielt and Yvonne Rasmussen, the laboratory technologist Hanne Lysdal Petersen and Ella Jessen are thanked for their skilful handling of diets, subjects, blood sampling and analysis of samples. Laboratory technicians Susanne Svalling and Pia Christensen, The University Hospital, Copenhagen, are thanked for the measurements of whole-body isotopic retention. Prof. Henryk Fandrejewski, The Kielanowski Institute of Animal Physiology and Nutrition, Polish Academy of Sciences, Jablonna, Poland and Dr Gunilla Lindahl, Danish Institute of Agricultural Sciences, Tjele, Denmark are thanked for providing the pork meat. This paper does not necessarily reflect the EU commission's views and in no way anticipates the commission's future policy in this area.

\section{References}

Ahn DU, Wolfe FH \& Sim JS (1993) Three methods for determining nonheme iron in turkey meat. J Food Sci 58, 288-291.

Andersen NL, Fagt S, Groth, MV, Hartkopp HB, Møller A, Ovesen L and Warming DL (1996) Danskernes kostvaner 1995, Hovedresultater (Dietary habits of the Danish population, Main results). Publication no. 235. Denmark: Levnedsmiddelstyrelsen (National Food Agency of Denmark).

Bæch SB, Hansen M, Bukhave K, et al. (2003) Nonheme-iron absorption from a phytate-rich meal is increased by the addition of small amounts of pork meat. Am J Clin Nutr 77, 173-179.

Becker A (2004) Nordic Nutrition Recommendations. www.norden.org.

Björn-Rasmussen E \& Hallberg L (1979) Effects of animal proteins in the absorption of food iron in man. Nutr Metab 23, 192-202.

Brune M, Rossander-Hultén L, Hallberg L, Gleerup A \& Sandberg A (1992) Iron absorption from bread in humans: inhibiting effects of cereal fiber, phytate and inositol phosphates with different numbers of phosphate groups. $J$ Nutr 122, 442-449.

Carlsson NG, Bergman EL, Skoglund E, Hasselblad K \& Sandberg AS (2001) Rapid analysis of inositol phosphates. J Agric Food Chem 49, $1695-1701$

Cook JD, Dassenko SA \& Lynch SR (1991) Assessment of the role of nonheme-iron availability in iron balance. Am J Clin Nutr 54, 717-722.

Fandrejewski H, Weremko W, Migdal S, Raj S \& Skiba G (2004) Mechanisms of compensatory growth in pigs. Fatty acids compositions and mineral retention. EU Workshop, Sustainable Pork Production: Welfare, Quality, Nutrition and Consumer Attitudes, Copenhagen, pp. 80-91.
Hallberg L, Brune M \& Rossander L (1986) Effect of ascorbic acid on iron absorption from different types of meals. Studies with ascorbic-acidrich foods and synthetic ascorbic acid given in different amounts with different meals. Hum Nutr Appl Nutr 40, 97-113.

Hallberg L, Brune M \& Rossander L (1989) Iron absorption in man: ascorbic acid and dose-dependent inhibition by phytate. Am J Clin Nutr 49, 140-144.

Hallberg L \& Hulthen L (2000) Prediction of dietary iron absorption: an algorithm for calculating absorption and bioavailability of dietary iron. Am J Clin Nutr 71, 1147-1160.

Hallberg L \& Rossander HL (1982a) Effect of different drinks on the absorption of non-haem iron from composite meals. Hum Nutr Appl Nutr 36A, 116-123.

Hallberg L \& Rossander L (1982b) Absorption of iron from Western-type lunch and dinner meals. Am J Clin Nutr 35, 502-509.

Hallberg L \& Rossander L (1982c) Bioavailability of iron from Westerntype whole meals. Scand J Gastroenterol 17, 151-160.

Hallberg L, Rossander L \& Skanberg AB (1987) Phytates and the inhibitory effect of bran on iron absorption in man. Am J Clin Nutr 45, 988-996.

Hallberg L \& Rossander-Hultén L (1991) Iron requirements in menstruating women. Am J Clin Nutr 54, 1047-1058.

Heath AL \& Fairweather-Tait SJ (2002) Clinical implications of changes in the modern diet: iron intake, absorption and status. Best Pract Res Clin Haematol 15, 225-241.

Hulten L, Gramatkovski E, Gleerup A \& Hallberg L (1995) Iron absorption from the whole diet. Relation to meal composition, iron requirements and iron stores. Eur J Clin Nutr 49, 794-808.

Hunt JR (2003) High-, but not low-bioavailability diets enable substantial control of women's iron absorption in relation to body iron stores, with minimal adaptation within several weeks. Am J Clin Nutr 78, 1168-1177.

Hunt JR \& Roughead ZK (2000) Adaptation of iron absorption in men consuming diets with high or low iron bioavailability. Am J Clin Nutr 71, 94-102.

Knudsen E, Sandström B \& Solgaard P (1996) Zinc, copper and magnesium absorption from a fibre-rich diet. J Trace Elements Med Biol 10, 68-76.

Layrisse M, Cook JD, Martinez C, et al. (1969) Food iron absorption: a comparison of vegetable and animal foods. Blood 33, 430-443.

Martinez-Torres C \& Layrisse M (1971) Iron absorption from veal muscle. Am J Clin Nutr 24, 531-540.

Monsen ER, Hallberg L, Layrisse M, et al. (1978) Estimation of available dietary iron. Am J Clin Nutr 31, 134-141.

Morck TA, Lynch SR \& Cook JD (1983) Inhibition of food iron absorption by coffee. Am J Clin Nutr 37, 416-420.

Reddy MB, Hurrell RF \& Cook JD (2000) Estimation of nonheme-iron bioavailability from meal composition. Am J Clin Nutr 71, 937-943.

Rossander L, Hallberg L \& Bjorn-Rasmussen E (1979) Absorption of iron from breakfast meals. Am J Clin Nutr 32, 2484-2489.

Samman S, Sandstrom B, Toft MB, et al. (2001) Green tea or rosemary extract added to foods reduces nonheme-iron absorption. Am J Clin Nutr 73, 607-612.

Wienk KJ, Marx JJ \& Beynen AC (1999) The concept of iron bioavailability and its assessment. Eur J Nutr 38, 51-75. 